\title{
Revista Brasileira de Enfermagem REBEn \\ Ensino de Enfermagem em Lajeado, RS: resgate histórico
}

\author{
Nursing teaching in Lajeado, RS: a historical recover \\ Enseñanza de Enfermería en Lajeado, RS: rescate historico
}

\section{Giselda Veronice Hahn}

Enfermeira. Mestre em Enfermagem. Docente do Curso de Enfermagem do Centro Universitário UNIVATES, Lajeado, RS

Endereco para contato

Rua José Kreling, 230, Cx. Postal 233,

Lajeado, RS - 95.900-000. giselda@bewnet.com.br

Justina Inês Brunetto Verruck Acker

Enfermeira. Mestre em Enfermagem pela UFSC. Coordenadora e Docente do Curso

de Enfermagem do Centro Universitário UNIVATES, Lajeado, RS.

fvacker@uol.com.br

\section{Ana Paula Wagner}

Acadêmica do $8^{\circ}$ semestre do curso de Enfermagem do Centro Universitário UNIVATES, Lajeado, RS, bolsista de iniciação científica. anapwagner@yahoo.com.br

Queli de Assis Trombini

Acadêmica do $5^{\circ}$ semestre do curso de Enfermagem do Centro Universitário UNIVATES, Lajeado, RS, bolsista de iniciação científica. tromsis@univates.br

\section{RESUMO}

Pesquisa qualitativa histórica, cujo objetivo foi resgatar a trajetória do ensino de Enfermagem no município de Lajeado, a partir da segunda metade do século passado. Utilizou-se como dados primários História Oral e como secundários, documentos, que foram analisados conforme a Análise de Conteúdo de Bardin. Os sujeitos foram alunos, professores e coordenadores de cursos de enfermagem. A profissionalização da enfermagem, na forma de cursos formais e informais, se intensificou nos últimos 50 anos, atendendo ao modelo político-econômico vigente. Os trabalhadores eram precariamente preparados e desenvolviam funções subalternas aos demais profissionais da saúde, ou seja, buscavam responder aos interesses dos médicos e dirigentes institucionais. Porém, a iniciativa de escolas e a atuação de diversos profissionais têm modificando esta realidade na região.

Descritores: História da enfermagem; Educação em enfermagem; Brasil.

\section{ABSTRACT}

Historical qualitative research whose aim has been to recover nursing teaching path in the Brazilian town of Lajeado/RS, from the second half of the twentieth century. Oral history has been used as primary data, and the second ones have been documents that have been analysed according to Bardin's Content Analysis. The subjects were heads, teachers and students of nursing courses. In the past 50 years, the professionalization of nursing was intensive, serving to the current political and economic model, in the form of formal and informal courses. Workers would be ill prepared, subservient to other health professionals and would try to work for doctors and institutional directors. However, school initiative and professionals working in various areas began to change this reality in the region.

Descriptors: History of nursing; Education, nursing; Brasil.

\section{RESUMEN}

Investigación cualitativa histórica, cuyo objetivo ha sido rescatar la trayectoria de la enseñanza de Enfermería en el municipio de Lajeado, desde la segunda mitad del siglo pasado. Como datos primarios se ha utilizado la Historia Oral y como secundarios los documentos, éstos analisados de acuerdo con el Análisis del Contenido de Cardin. Los sujetos fueron alumnos, profesores, y coordinadores de los cursos de Enfermería. El profesionalismo de Enfermería ha sido intenso en los últimos 50 años, a causa del modelo político-económico, y fue hecho con cursos formales e informales. Los trabajadores eran escasamente preparados, desarrollaban funciones subalternas para los otros profesionales de salud y buscaban responder a los intereses de médicos y dirigentes institucionales. Pero, la iniciativa de escuelas y la actuación de distintos profesionales ha cambiado esta realidad en la región.

Descriptores: Historia de la enfermería; Educación en enfermería; Brasil.

Hahn GV, Acker JIBV, Wagner AP, Trombini QA. Ensino de Enfermagem em Lajeado, RS: resgate histórico. Rev Bras Enferm 2006 set-out; 59(5): 666-74.

\section{INTRODUÇÃO}

Este artigo é resultado de pesquisa desenvolvida por alunos e professores do Curso de Enfermagem da UNIVATES - Centro Universitário, de Lajeado, RS. Nosso objetivo geral foi resgatar a trajetória do ensino de enfermagem no município de Lajeado a partir da segunda metade do século passado. Especificamente procuramos identificar a construção dos saberes e das práticas de enfermagem; descrever as características das instituições formadoras e dos cursos oferecidos; e relacionar o ensino de enfermagem com as políticas públicas vigentes na época.

A partir da pesquisa histórica, busca-se o entendimento da realidade através da análise dos fatos
Submissão: $11 / 01 / 2006$

Aprovação: $23 / 06 / 2006$ 
passados. No que diz respeito à enfermagem, conhecer e recontar este processo facilitará a compreensão dos saberes e das práticas atuais, pois (...) a compreensão de qualquer área do conhecimento está estritamente relacionada às suas origens, suas raizes, tornando-se, portanto, necessário buscar na história explicações para fatos ocorridos atualmente ${ }^{(1)}$.

O resgate histórico do ensino de enfermagem a partir da segunda metade do século passado no município de Lajeado vem integrar um contexto mais abrangente sobre a história da enfermagem, pois vários estudos e publicações têm sido divulgados, visando conhecer e registrar os antecedentes históricos da profissão.

Esta reconstrução visa subsidiar a reflexão acerca das transformações dos saberes e práticas da enfermagem, nos diversos momentos de nossa organização social. Além disso, oferece uma visão do desenvolvimento da sociedade local, propiciando o entendimento da organização do ensino de enfermagem de acordo com a realidade vivida.

Revisitar a história da enfermagem não tem o objetivo de apenas recuperar uma seqüência de dados cronológicos, mas de buscar os fatores que condicionaram e determinaram o desenvolvimento dessa profissão em nosso país, bem como refletir sobre o papel do profissional e a sua atuação na área da saúde. Muitos dos problemas vividos hoje pela enfermagem produziramse no passado e se reproduzem no presente; por isso, a investigação é necessária para seu desvendamento e superação(2).

Acreditamos que a reflexão oportunizada pelos conhecimentos construídos contribuirá para o fortalecimento e o reconhecimento da enfermagem como uma profissão, em nível local e nacional.

\section{METODOLOGIA}

A busca de identidade é uma das necessidades fundamentais da sociedade humana até hoje. Esta busca é elemento essencial à memória, cujo suporte é o grupo social. A identidade é percebida e construída permanentemente, pressupondo um elo com a história passada e com a memória do grupo. Quando acaba a memória, começa a história ${ }^{(3) .}$

Como objetivo de resgatar a história do ensino de enfermagem no município de Lajeado, optou-se pela pesquisa qualitativa, de caráter descritivo, utilizando a metodologia da História Oral e da Análise Documental, sendo os dados coletados submetidos à Análise de Conteúdo de Bardin ${ }^{(4)}$.

A coleta de dados foi realizada através de entrevista semi-estruturada tendo por base três categorias pré-definidas: 1) Características das instituições formadoras e dos cursos; 2) Motivação dos sujeitos e significado do processo de ensino na construção do saber; 3) Enfoque do ensino e as políticas vigentes.

História oral é um método de pesquisa que privilegia a realização de entrevistas com pessoas que testemunharam acontecimentos, como maneira de se aproximar do objeto de estudo. A análise documental permite obter e complementa informações que não podem ser investigadas a partir da observação direta ou por entrevistas ${ }^{(5)}$.

A pesquisa foi realizada com 28 sujeitos que viveram o processo ensinoaprendizagem de enfermagem no período do estudo, entre eles, docentes enfermeiros e médicos, alunos, diretores de escolas e coordenadores de curso. Identificamos três instituições, um hospital e duas escolas (uma de nível fundamental e médio e outra um Centro Universitário), que atuaram no período estudado e que ofereceram cursos formais ou informais. Foi solicitada a assinatura do Termo de Consentimento Livre e Esclarecido, conforme preconiza a resolução 196/96 do Conselho Nacional de Saúde.

Aanálise documental tem como base os registros que constam em currículos de cursos, certificados, pareceres de autorização e fotografias, das três instituições envolvidas na formação.

\section{EMBASAMENTO TEÓRICO}

Registrar a história do ensino de enfermagem revela a necessidade de uma compreensão crítica das práticas de enfermagem. A história da enfermagem não se processa em um espaço abstrato. Ao contrário, ela se dá num espaço concreto na sociedade brasileira, com seus determinantes políticos, históricos e ideológicos, sendo, portanto, altamente influenciável pelas ações e decisões tomadas nestes campos. A coleta de fatos históricos deve passar por um processo de análise que evidenciará as relações da enfermagem com a sociedade e com o Estado.

Pesquisadores da história da enfermagem revelam que a formação do enfermeiro esteve vinculada aos interesses dominantes, formando profissionais que atendessem às necessidades do sistema político vigente ${ }^{(1,2,6,7)}$.

$O$ perfil do enfermeiro no Brasil, consonante como o modelo social e econômico vigente, começou a ser delineado por volta de 1543 , quando são construídas as primeiras Santas Casas com o objetivo de isolar os pobres, os doentes e os órfãos.

(...) o pobre tem necessidade de assistência e, como doente, portador de doença e de possível contágio, é perigoso. Por estas razões, o hospital deve estar presente tanto para recolhê-lo, quanto para proteger os outros do perigo que ele encarna ${ }^{(8)}$.

As Santas Casas tinham um cunho puramente curativo e destinavam-se aos enfermos miseráveis. A assistência prestada caracterizava-se como atividade religiosa, cujos exercentes demonstravam alto grau de obediência, respeito à hierarquia, humildade e espirito de servir.

A ideologia da enfermagem desde sua origem (...) significa: abnegação, obediência, dedicação. Isso marcou profundamente a profissão de enfermagem - o enfermeiro tem que ser alguém disciplinado e obediente. Alguém que não exerça a crítica social, porém console e socorra as vítimas da sociedade ${ }^{(1)}$.

A formação do enfermeiro é ditada pelas necessidades de atendimento apresentadas pela população no final do século XIX e início do século XX. Grandes problemas de saúde pública assolavam o país neste período. Epidemias como febre amarela, varíola e peste bubônica desafiavam uma nova organização sanitária. Diversas medidas foram instituídas com o objetivo de controlar as doenças, entre elas a criação do serviço de assistência gratuita aos pobres e o serviço de inspeção sanitária que realizava visitas periódicas a navios, mercados, prisões, hospitais, colégios, igrejas. Era a chamada Polícia Sanitária ${ }^{(2)}$.

O modelo sanitarista foi muito contestado pela imprensa, pelos intelectuais e pela população devido ao seu caráter autoritário. As medidas não visavam à melhoria da qualidade de vida da população e à prevenção dos problemas de saúde.

Neste mesmo período, a economia girava em torno da exportação do café. Havia, nos portos do Rio de Janeiro e de Santos, uma grande circulação de pessoas, entre elas, negros e escravos brasileiros e estrangeiros. Nessa mesma época, o Brasil entra numa crise comercial, pelo fato de ocorrerem epidemias de febre amarela, as quais atingiram os tripulantes dos navios estrangeiros, levando muitos deles à morte. Os dirigentes brasileiros eram constantemente advertidos pelos países com quem mantinham relações comerciais sobre os riscos de contaminação. Conseqüentemente, o saneamento dos portos era uma exigência para a continuidade da comercialização.

Oswaldo Cruz é chamado para controlar as epidemias e inicia uma grande campanha prevencionista. Em quatro anos são controladas a febre amarela, a peste e a varíola. Carlos Chagas deu continuidade ao trabalho iniciado por Oswaldo cruz e criou, em 1921, o curso de Visitadoras Sanitárias, sendo função da enfermeira-visitadora, como educadora sanitária, difundir medidas de prevenção de doenças nas residências, nos portos e comunidades em geral. Surge, assim, a Enfermagem Moderna no Brasi ${ }^{(1,2)}$.

\subsection{Ensino profissional de enfermagem no Brasil}

Os antecedentes históricos que marcaram o início da profissionalização da enfermagem no Brasil estão relacionados ao surgimento de cursos de parteiras junto às faculdades de medicina do Rio de Janeiro (1832) e da Bahia (1808)(7).

A primeira escola de enfermagem surgiu em 1890, junto ao Hospital Nacional dos Alienados, também chamado Hospício Pedro II, através do 
Decreto ${ }^{0} 791$, de 27/09/1890, no Rio de Janeiro. Passou a denominar-se Escola de Enfermeiros Alfredo Pinto e tinha a função de preparar profissionais para atuar nos hospitais. As aulas eram dadas pelos médicos. Funcionou em condições precárias até ser reorganizada em 1959.

Em São Paulo, surgem as escolas de Enfermeiras do Hospital Samaritano em 1901; e a escola de Parteiras, em 1902.

Em 1916, a Cruz Vermelha Brasileira cria a sua escola, fruto de um movimento internacional para melhorar as condições de assistência aos feridos da Primeira Guerra Mundial.

Foi, porém, a criação da escola de Enfermagem do Departamento Nacional de Saúde Pública, pelo médico Carlos Chagas, em 1922, que marcou o início do ensino formal de enfermagem no Brasil. Um grupo de enfermeiras norteamericanas, chefiadas por Ethel Parsons e Clara Louise Kienninger, organizou a escola nos moldes da escola britânica de Florence Nightingale, considerada precursora da enfermagem profissional no mundo.

Em 1926, esta escola passa a chamar-se escolaAna Néri, em homenagem a à voluntária brasileira que auxiliou no cuidado aos feridos na Guerra do Paraguai. Em 1931, o educandário é decretado padrão por Getúlio Vargas, através do Decreto 20.109, que também estabelece que todo o ensino de enfermagem, para ser considerado válido, deveria estar baseado no currículo desta escola ${ }^{(7)}$.

Inicialmente, o curso tinha a duração de três anos acadêmicos ou 28 meses letivos. Já a segunda turma passou para quatro anos ou 36 meses. Era dividido em cinco fases, sendo que naúltima o enfoque era a especialização em enfermagem clínica, de saúde pública ou administração hospitalar. As candidatas passavam por uma seleção em que se exigia o diploma de normalista ou, na ausência deste, as candidatas tinham que provar sua capacitação. Havia a obrigatoriedade de oito horas de estágio no Hospital São Francisco de Assis, que dava direito à residência, pequena remuneração mensal e duas folgas e meia por semana.

O modelo de ensino trazido pelas enfermeiras norte-americanas e praticado no Brasil foi uma adaptação distorcida do modelo utilizado por Nigthingale na Inglaterra.

As Escolas de Enfermagem dos Estados Unidos da América, fundadas nas décadas finais do século passado e no início deste (XX), estavam diretamente vinculadas a hospitais particulares, servindo a seus interesses imediatos de mão-de-obra e de diminuição de custos, o que redundava em hipertrofia das atividades práticas dos alunos ${ }^{(7)}$.

Embora a necessidade de enfermeiras no Brasil, por ocasião do início de sua profissionalização, ocorresse na Saúde Pública, o modelo seguido estava voltado às necessidades apresentadas pelos hospitais. Este modelo de ensino da enfermagem seria seguido no país.

Como podemos perceber, o início da profissionalização da enfermagem, através da primeira escola considerada padrão para todo o país, foi marcada por contradições. Inicialmente, a demanda por atendimento concentrava-se na saúde pública, sendo exigida das enfermeiras uma escolarização em nível de países desenvolvidos. Exigiam-se muitas horas de estágio nos hospitais. Além disso, a adaptação do modelo norte-americano praticado no Brasil evidenciou outra contradição. Nos Estados Unidos, assim como na Inglaterra, as enfermeiras eram também preparadas para a administração, a supervisão e o ensino, enquanto a demanda de atendimento no Brasil, tanto em nível hospitalar como na saúde pública, era prioritariamente a execução do trabalho de enfermagem e não somente as funções administrativas.

Seguindo os ditames da economia da época, a população feminina foi considerada ideal para executar as atividades de enfermagem, as quais eram entendidas como uma extensão do trabalho doméstico. Da classe operária provinhamas enfermeiras responsáveis pela prestação do cuidado propriamente dito, enquanto a burguesia fornecia as enfermeiras que ocupavam os cargos gerenciais e administrativos.

A divisão técnica entre os dois tipos de enfermeiras que atuavam no Brasil exigia uma separação das atividades que ambas deveriam executar. Surgem, assim, as técnicas de enfermagem como as primeiras expressões do saber.
As técnicas de enfermagem (...) representavam efetivamente a primeira expressão do saber de enfermagem. As técnicas representavam a sistematização das atividades desenvolvidas pelos trabalhadores de enfermagem, de modo a racionalizar o trabalho, com o objetivo de conseguir o melhor resultado com o menor custo. É a aplicação dos princípios Tayloristas sobre a gerência científica, onde o gerente controla o processo de trabalho que os demais trabalhadores executarão de forma parcelada ${ }^{(6)}$.

A racionalização proposta pela sistematização das técnicas de enfermagem visa atingir economia de tempo, energia e dinheiro, atendendo aos interesses do capital, o que demonstra a submissão da enfermagem a estes interesses. Estas técnicas de enfermagem consistem na descrição dos procedimentos de enfermagem a serem realizados, etapa por etapa, como também descrevem o material a ser utilizado. Além disso, referem-se a procedimentos realizados junto aos indivíduos, bem como incluem tarefas administrativas, como admissão e alta do paciente.

As atividades ou cuidados prestados através das técnicas de enfermagem eram desempenhados de forma empírica pelos primeiros práticos que atuavam nos hospitais, mas foram apropriados pelos enfermeiros que os sistematizaram e os transformaram em saber de enfermagem a ser utilizado como serviço e executado pelo pessoal auxiliar sob controle gerencial do enfermeiro.

A evolução do conhecimento de enfermagem, que passou do pensamento místico, mágico e até experimental das sociedades tribais ao conhecimento da ciência racional, foi marcada ainda pelo surgimento da Associação Brasileira de Enfermeiros e Enfermeiras, em 1926, que visava congregar as alunas formadas pela primeira turma da Escola Ana Neri. Tinha como principal objetivo elevar os padrões de saúde da população(1).

A partir da criação desta associação e da participação de enfermeiras no Congresso do Conselho Internacional de Enfermeiras em Montreal, no Canadá, foi considerado indispensável a existência de uma revista que auxiliasse no desenvolvimento da profissão, criando-se, assim, Os Annaes de Enfermagem, em 1932. Este referencial é utilizado como instrumento de educação de estudantes, professores e profissionais de enfermagem, na medida em que procura imprimir uma direção intelectual, uma concepção de enfermagem e de mundo uniforme para todo o Brasil.

Finalizando, buscou-se aqui demonstrar os principais fatos que marcaram a história da enfermagem, o caminho percorrido pela enfermagem no Brasil, as influências recebidas e ações realizadas, as quais configuraram o surgimento da enfermagem profissional no país.

\section{RESULTADOS}

Para realizar o resgate histórico do ensino da enfermagem em Lajeado, RS a partir da segunda metade do século passado, foram entrevistados sujeitos oriundos de diferentes cursos e de diferentes instituições formadoras, totalizando 28 pessoas: 15 alunos, 11 organizadores e co-organizadores e ou professores que tinham, na época da realização de seus cursos, idades entre 18 e 40 anos, sendo 26 do sexo feminino e 2 do sexo masculino.

Os resultados foram agrupados em cinco categorias: 1) Características das instituições formadoras; 2) Características dos cursos; 3) Motivação dos sujeitos para a busca do saber; 4) Significado do processo de ensino para os envolvidos; 5) 0 ensino da enfermagem e as políticas de saúde e educação.

\section{Categoria 01: Características das Instituições Formadoras}

A partir da análise dos dados, constatou-se a existência de cursos formais e informais realizados em três principais instituições formadoras: um hospital, uma escola de nível fundamental e médio e uma escola de nível superior, sendo que alguns tiveram parcerias locais e estaduais.

Além destas instituições, constatamos a participação de diversas entidades sociais e educacionais que contribuíram para a formação de profissionais naárea da enfermagem. Porém, devido ao grande número de cursos einstituições envolvidas e a dificuldades enfrentadas no acesso às informações, não serão relatadas detalhadamente aqui, apenas apresentadas esquematicamente no quadro 1. 
Identificamos, inicialmente, um hospital como primeira instituição formadora, fundado em 1933. Prestava basicamente atendimento aos pobres, por ser uma sociedade de beneficência e caridade. As pessoas vinham de longe, hospedavam-se em casas, albergues, hospedarias e hotéis para receber atendimento médico e de parteiras ${ }^{(9)}$.

Atualmente, este hospital exerce grande influência na saúde em nível regional, tanto terapêutica quanto diagnóstica, devido à sua capacidade humana e tecnológica em diferentes áreas do conhecimento. Percebe-se forte influência desta instituição no processo de ensino da enfermagem, especialmente em relação às parcerias formadas junto a profissionais da saúde (médicos, religiosas, enfermeiras) e a instituições de ensino.

Constatamos, também, a participação de uma escola de ensino fundamental e médio na formação de Técnicos de Enfermagem. Foi fundada em 30 de janeiro de 1897 e respondeà necessidade social de prestar serviços à educação da Infância e da Juventude. "Optou por um modelo de educação que ensina não somente os conhecimentos humanos capazes de formar a pessoa humana para ser um profissional competente, mas formar seu coração para fins superiores"(9). É uma instituição particular, de cunho religioso-católico. Além de ter oferecido o curso Técnico em Enfermagem nas décadas de 70 e 80, mantém, atualmente, cursos na área da educação geral (Educação Infantil, Ensino Fundamental e Médio) e na formação de professores de nível médio.

Por último, identificamos uma Instituição de Ensino Superior (IES), que desde 1989 tem contribuído no processo de ensino da enfermagem, através da formação de auxiliares, técnicos e enfermeiros.

Esta IES foi criada na década de 1969 como extensão de uma Universidade próxima, funcionando com apenas alguns cursos nas áreas daAdministração e Letras em colégios da cidade. Hoje conta com 51 cursos de extensão, 08 técnicos, 02 seqüenciais, 36 de graduação e 20 de pós-graduação, com um total de 8.422 alunos. Esta Instituição mantém como objetivo principal, ao longo de sua história, o desenvolvimento regional e participativo da comunidade, colaborando para seu crescimento e desenvolvimento.

(...) Está engajada positivamente nesta transformação, acompanhando uma tendência de qualificação das ações e serviços da saúde. Na última década vem dando importantes passos na direção de também especializar-se na formação de trabalhadores em saúde. Inicialmente, desenvolvendo cursos de formação de auxiliares e técnicos de enfermagem, hoje passou a oferecer educação superior ${ }^{(10)}$.

\section{Categoria 02: Características dos cursos}

Apresentamos a seguir o quadro 1, que contém as características do ensino formal e informal de enfermagem realizados no período em estudo, em Lajeado. Pode ser observado que houve a participação de várias instituições na oferta de diversos cursos. Constatamos, também, uma lacuna de informações no período anterior a 1972.

O hospital foi o pioneiro na preparação do pessoal de enfermagem. Sediou $01^{\circ} \mathrm{e} 02^{\circ}$ Curso Intensivo de Enfermagem, organizado por um médico recém formado, o qual contou com a participação de seus colegas e das religiosas que administravam a instituição na época. Os cursos ocorreram em $1972 \mathrm{e}$ em 1973. Nesta mesma instituição, em 1975, ocorreu o curso de Noções Básicas de Atendimento Psiquiátrico, organizado por uma religiosa e por um médico que ministrou as aulas. Este dado provavelmente coincide com 0 processo de institucionalização dos pacientes com problemas mentais, em Lajeado.

O curso Técnico em Enfermagem, planejado a partir de muitos encontros com os responsáveis pelos hospitais da região, foi oferecido por uma escola de ensino fundamental e médio, no período de 1975 a 1985 . Foi organizado por uma inspetora de ensino, professora de matemática e esposa de médico e aprovado pela Portaria $n^{\circ} 2.386$, em 3 de março de 1975 para formar os denominados 'enfermeiros', porém, com um certificado de Técnico em Enfermagem.

Depois de ter formado 231 enfermeiros, o curso Técnico de Enfermagem de $2^{\circ}$ grau foi extinto em 1985, devido à desvalorização do mercado de trabalho para os alunos concluintes, dificuldade de manter o curso por falta de elemento humano para coordenar e professores habilitados para atuarem no mesmo $^{(9)}$.

Nos anos de 1976 e 1982, foram realizados cursos de Atendente Hospitalar

\begin{tabular}{|c|c|c|c|c|c|}
\hline $\begin{array}{l}\text { Tipo de } \\
\text { Ensino }\end{array}$ & $\begin{array}{l}\text { Número de } \\
\text { turmas }\end{array}$ & $\begin{array}{c}\text { Cursos } \\
\text { Pareceres }\end{array}$ & $\begin{array}{l}\text { Forma de } \\
\text { Seleção }\end{array}$ & Período de Ocorrência & $N^{0}$ de Egressos \\
\hline Informal & 02 & Intensivo de Enfermagem & Convite & 1972 e 1973 & Não identificado \\
\hline Informal & 01 & Noções básicas de Psiquiatria & Convite & 1975 & Não identificado \\
\hline Informal & - & Programa de Educação Continuada / PEC & $\begin{array}{l}\text { Interessados da área médica e } \\
\text { enfermagem }\end{array}$ & Entre 1974 até 1978 & Não identificado \\
\hline Informal & 02 & Atendente Hospitalar & Convite & 1976 e 1982 & Não identificado \\
\hline Formal & 05 & $\begin{array}{l}\text { Técnico em Enfermagem } \\
\text { Parecer no1156/74 }\end{array}$ & $\begin{array}{l}\text { Entrevista, teste e curso } \\
\text { preparatório }\end{array}$ & 1975 até 1985 & 231 \\
\hline Formal & 01 & $\begin{array}{l}\text { Supletivo de Qualificação de Auxiliar de } \\
\text { Enfermagem } \\
\text { Parecer } 184 / 90\end{array}$ & Teste escrito e entrevista & $1987 / 89$ & 56 \\
\hline Formal & 08 & $\begin{array}{l}\text { Supletivo de Qualificação Profissional de } \\
\text { Auxiliar de Enfermagem Pareceres n } n^{0} 134 / 89 \text {, } \\
\text { 922/94 e 826/96 }\end{array}$ & Teste escrito e entrevista & 1989/1999 & 290 \\
\hline Formal & 02 & Auxiliar de Enfermagem -conveniado & Inscrição com entrevista & 1997 & 53 \\
\hline Formal & 03 & $\begin{array}{l}\text { Técnico - Complementação } \\
\text { Parecer no 1134/98 }\end{array}$ & Inscrição & A partir de 2001 & 200 \\
\hline Formal & 04 & Técnico de Enfermagem & Inscrição e prova seletiva & A partir de 1999 & 105 \\
\hline Formal & 01 & Especialização em Enfermagem do Trabalho & Inscrição & 2004 & 09 \\
\hline Formal & 10 & $\begin{array}{l}\text { Bacharelado em Enfermagem } \\
\text { Portaria de reconhecimento no 3799/2004 }\end{array}$ & Vestibular & A partir de 2000 & 19 \\
\hline
\end{tabular}

Quadro 1. Distribuição dos cursos de enfermagem e suas características no município de Lajeado-RS. 
no referido hospital em parceria com o Serviço Nacional de Aprendizagem Comercial - SENAC. O último, o de 1982, foi organizado pela enfermeira chefe de enfermagem do hospital, que também ministrou as aulas. Em relação ao curso de 1976, localizamos apenas um certificado emitido por representantes do SENAC.

O primeiro curso de Auxiliar de Enfermagem realizado em Lajeado ocorreu no mesmo hospital, em 1988. Também foi organizado pela enfermeira chefe do serviço de enfermagem em parceria com uma Universidade localizada em município vizinho. Os certificados foram emitidos somente em 1991, devido à demora de reconhecimento de cursos realizados fora da sede (Universidade).

Entre os anos de 1989 a 1999, na IES, ocorreram cursos Supletivos de Qualificação Profissional de Auxiliar de Enfermagem, conforme pareceres de autorização e funcionamento n 134/89, 922/94 e 826/96. Neste período de 10 anos, foram constituídas 08 turmas, habilitando 290 Auxiliares de Enfermagem, perfazendo uma média de 29 alunos por ano. Segundo documentos analisados, a maioria dos alunos é oriunda de municípios da região do Vale do Taquari RS.

Paralelo ao curso Supletivo de Auxiliar de Enfermagem da própria instituição, houve, no ano de 1997, o curso de Qualificação Profissional de Auxiliar de Enfermagem, promovido pelo Ministério do Trabalho e Secretaria do Trabalho, Cidadania e Assistência Social do RS, tendo como entidade gestora outra universidade gaúcha. Formou 53 alunos em duas turmas. Ocorreu sem ônus para os alunos e na mesma IES mencionada inicialmente.

Na área de enfermagem, a inovação foi a realização do Curso Supletivo de Qualificação Profissional para Auxiliares de Enfermagem, no período de 1987 a 1989 e em 1991, profissionalizando em massa os atendentes de enfermagem no Rio Grande do Sul. Este é um dos motivos pelo qual o Rio Grande do Sul é um dos estados do país com mais baixo índice de atendentes de enfermagem (categoria ocupacional) em relação a presença de auxiliares de enfermagem (categoria profissional) ${ }^{(11)}$.

A partir da extinção do curso de Auxiliar de Enfermagem na IES, em 1999, é criado o curso Técnico de Enfermagem que continua até os dias de hoje. Em 17 de dezembro de 1998, este curso foi autorizado para egressos de $2^{\circ} \mathrm{grau}$, conforme Parecer $n^{0} 1.134 / 98$ (CEED). A grande procura pelo curso estimulou o Centro Universitário a oferecer Curso Técnico em outros campi da instituição, localizados nas cidades de Encantado e Taquari. Nesta mesma época, é iniciada a elaboração de dois projetos de cursos de especialização para o Técnico de Enfermagem, sendo um em Unidade de Terapia Intensiva e o outro em Enfermagem do Trabalho. Neste último, formou-se apenas uma turma, no ano de 2004.

No ano de 1999, inicia-se o planejamento do curso Bacharelado em Enfermagem, cujo funcionamento foi autorizado conforme Resolução $n^{0} 36$ (26/05/2000), tendo sido realizado o primeiro vestibular em 2000 B. 0 reconhecimento pelo INEP/MEC deu-se através da Portaria n 3799 , de 17 de novembro de 2004. A fala do Sujeito 24 (S. 24) esclarece esta trajetória:

(...) nessa trajetória histórica a instituição tem procurado dar sua contribuição para a enfermagem... está fazendo história na enfermagem aqui na região, ela tem uma grande importância, uma grande participação quando oferece esses cursos. Tem a vantagem do nosso aluno poder ficar aqui na região e não precisar se deslocar por grandes distâncias para adquirir sua formação e, ao mesmo tempo, ela prepara o aluno que conhece a região (...) (S. 24)

Os cursos de enfermagem da instituição são realizados em parceria com instituições conveniadas da região do Vale do Taquari, a qual abrange mais de 40 municípios, entre elas hospitais, prefeituras, Coordenadoria Regional de Saúde, empresas, clínicas de acolhimento e de reabilitação.

Categoria 03: Motivação dos sujeitos para a busca do saber

Nesta categoria buscamos agrupar os motivos pelos quais os sujeitos da pesquisa participaram do processo de ensino. Percebemos que muitos sujeitos sentiram-se motivados para o ensino a partir de uma necessidade pessoal e sócio-econômica, possivelmente para obter aperfeiçoamento, qualificação, trabalho e renda. Os sujeitos buscavam atingir metas pessoais e sociais, as quais refletem o potencial da enfermagem estar em constante transformação.

(...) vim com a finalidade de fazer o curso (...) sempre tinha vontade, eu em casa trabalhava com chás (...) meus pais não tinham condições de pagar o estudo (..). tinha que adquirir por si mesmo (S. 02).

O ensino da enfermagem é uma bola de neve, depois que iniciamos, sempre queremos mais (...) iniciei limpando chão do hospital, depois fui copeira, atendente de enfermagem sem ter feito curso e depois de alguns anos (...) tornei-me enfermeira (S. 26).

\section{(...) eu estava atrás de um serviço e foi mais por curiosidade (S. 23).}

(...) fiz o curso pornecessidade e também para a busca de aperfeiçoamento, temos que correr atrás (S.17).

(...) trabalhava em fábrica de calçados e fiz o curso (...) para melhorar a condição econômica (S. 21).

Também constatamos que a motivação para algumas pessoas, em especial aquelas que realizaram os primeiros cursos informais em 1972, foi atender às necessidades médicas dentro dos hospitais, talvez por não terem claro 0 verdadeiro objeto do cuidado da enfermagem, o ser humano, ou por não compreenderem a qualificação profissional como algo indispensável para o desenvolvimento da profissão. Provavelmente, a razão deste entendimento está no fato da enfermagem não estar profissionalizada e, portanto, não ser reconhecida socialmente. Esta realidade foi mudando aos poucos, a partir da iniciativa da escola de ensino fundamental e médio em realizar o primeiro curso profissionalizante na enfermagem, ou seja, o Curso Técnico em Enfermagem.

(...) os médicos (na década de 70) sentiram que nos estávamos muito por fora, então eles começaram a fazer cursos (S. 06).

(...) gostava de ajudar o cirurgião, porque lá você não lidava direto como paciente, mas ajudava o médico (S. 08).

A partir da década de 70 , alguns sujeitos sentiram-se motivados para 0 ensino a partir do mundo do trabalho, almejando funções que Ihes trariam maior status social, que, no entender deles, era a prática da enfermagem.

(...) o objetivo maior era chegar na enfermagem, era um sonho, a gente via o pessoal todo faceiro, estavam progredindo, ganhando mais espaço para chegar na enfermagem, acho que isto era o objetivo maior do pessoal que trabalhava no hospital (S. 11).

(...) sonhava ser 'enfermeira', via elas trabalhando enquanto eu limpava o chão (....) quando eu tinha tempo ajudava elas a dar banho e atender as campainhas (S. 26).

Em alguns casos, a motivação para o aperfeiçoamento e atualização em enfermagem era um investimento pessoal e estava associado a um Programa de Educação Continuada para médicos, o PEC

(...)chamavam aquilo de PEC, eles faziam um estudo cada sábado do mês ou a cada 14 dias (...) vinham profissionais de enfermagem de POA (...) cada um trazia assuntos para serem debatidos (...) nós fomos até para São Paulo fazer um curso de bloco cirúrgico, por conta própria, nós que bancamos (...) (S. 02). 
Às vezes, a busca do ensino da enfermagem também se dava por vocação, doação, religiosidade, experiência de doença na família ou a partir do incentivo de familiares ou chefias nos postos de trabalho.

(...) fiz o curso (...) motivada por doença na família, por gostar de lidar com pessoas, ajudar, conversare cuidar (S. 20).

(...) fiz cursinhos e segui trabalhando como voluntária e até que eu tive chance de entrar para a enfermagem (...) (S. 22).

Fui fazer o curso, incentivada pelo fisioterapeuta (...) que se preocupou com o meu futuro (S.12).

(...) fui convidada (...) estava trabalhando na enfermagem mesmo sem ter feito curso (...) (S. 09)

Devo muito a meus familiares e ao médico com quem eu trabalhei (...)(S. 26).

(...) eu não tinha conhecimento do que era a enfermagem, então tinha alguma coisa que me levava, é que minha mãe está na área (é Técnica de Enfermagem) (S. 27).

Temos, ainda, outro grupo de sujeitos que participou do processo de ensino para atender às exigências legais, surgidas entre as décadas de 70 e 80, que, certamente, contribuíram com o desenvolvimento da profissão. Este objetivo pode ser percebido nestas falas:

(...) para fazer um projeto dessa natureza (Técnico de Enfermagem), pensei mais nos anseios da própria comunidade (...) pessoas mais classificadas atenderiam melhor os paciente (...) (S. 05).

(...) como enfermeira, não treinava o pessoal para atendente ... era contra o meu conselho (o entrevistado se refere a Lei do Exercício Profissional, $\left.n^{\circ} 7498\right)$ (...) não mantivemos o treinamento de atendentes, isto era ilegal (S. 07).

(...) a gente precisava de profissionais que fossem formados dentro desse contexto do Vale do Taquari (S. 28).

Identificamos que o processo de ensino para o desenvolvimento da profissão aconteceu de forma lenta, pois, mesmo sendo oferecido um Curso Supletivo de Qualificação Profissional gratuito aos atendentes de enfermagem no ano de 1997, sobraram vagas, que foram preenchidas por pessoas leigas que buscavam um trabalho/profissão.

(...) esse curso era uma chance para os atendentes que não tinham condições para fazer o curso (...) e muita gente não levou a sério... (S. 23).

Por outro lado, a motivação pela busca do saber em enfermagem é um crescente. Os profissionais sentem a necessidade de adquirir novos conhecimentos e a academia se mobiliza de diferentes modos para atender a essas demandas.

(...) nós observamos também que os alunos retornam a instituição, muitos alunos que fizeram o auxiliar, ou mesmo o técnico, depois fizeram a complementação de estudos para o técnico, e talvez até hoje estejam começando a graduação (...) na enfermagem, tem sempre coisas novas para aprender (...) (S. 24).

Categoria 04: significado do processo de ensino para os envolvidos A análise das entrevistas também evidenciou que o ensino da enfermagem gerou diferentes significados para a mesma pessoa. De certa maneira, estes significados refletem a compreensão dos sujeitos acerca dos conceitos da profissão. Esta compreensão, mesmo impregnada de subjetividade, permite conhecer o significado do ensino de enfermagem em Lajeado.

Para os sujeitos do estudo, o significado de ensino da enfermagem está interligado ao cotidiano, a realizações pessoais e profissionais, a prazer $\mathrm{e}$ sofrimento. Percebemos que nas primeiras décadas do período em estudo, 0 significado do processo de ensino recebeu forte influência das religiosas e dos médicos. E, mesmo tendo caráter disciplinador e técnico, era incentivada a importância das relações humanas no ensino da enfermagem.

Ao apresentarmos o primeiro grupo de relatos que emergiram na quinta categoria, os sujeitos revelaram encontrar no ensino da enfermagem realização pessoal, satisfação e prazer em ensinar, treinar e aprender, independente da função que desempenhavam na prática da enfermagem, na educação e na medicina.

(...) na época as irmãs achavam ou viam quem tinha condições de desenvolver aquele trabalho (...) era como se fossem enfermeiras experientes, viam certas coisas em certos alunos, quem podia atuar na enfermagem (...) (S. 13).

(...) gosto de ensinar pessoas, passar, ensinando tu estás te imortalizando pelo ensino e deixando a maior coisa que podes fazer na vida (S. 10).

(...) me realizei, acho que tinha dentro de mim esta profissão, nas brincadeiras de infância estraguei uma boneca porque eu era a pessoa que sempre fazia as injeções (S. 23).

(...) valeu a pena, faço meu trabalho por paixão (...) na vida a gente tem ganhos e perdas (S. 12).

(...) fomos pioneiros (...) esses cursos (Auxiliar e Técnico de Enfermagem) foram o embrião (...) resultando no curso de enfermagem (graduação) (S. 15).

Mesmo que o ensino tenha sido gratificante e prazeroso, os entrevistados salientam a importância da cobrança e da rigidez do professor. Aimagem do professor tem forte conotação sobre o aprendizado. Arigidez é entendida como atributo necessário para a qualidade do ensino. Entre os entrevistados, alguns dizem que 'já não se faz mais como antigamente', o que revela uma supervalorização do ensino técnico e da prática, em detrimento do ensino atual, que se apresenta de forma abrangente e fundamentado em valores éticos, técnicos, científicos, filosóficos, culturais e estéticos, que busca desenvolver habilidades e competências para o Ser e o Fazer da enfermagem. Talvez a supervalorização do 'fazer' da Enfermagem seja pelo fato de ter absorvido o saber técnico para atender às demandas da medicina e por não perceberem a enfermagem como profissão autônoma e como ciência e arte.

(...) eles (os médicos) eram muito preocupados para que a gente fosse bem, e eram bastante rigorosos (S. 14).

O interessante, que me chamava atenção (na década de 1980), era mais fácil dar aula, disciplinar os alunos novos que não tinham noção da enfermagem do que aqueles que já tiveram o curso de atendente e já atuavam no hospital (...) vinham com certos vícios. Tinha que ser bem rígida (...) (S. 03).

Acho que era mais exigido que agora (...) hoje em dia eles se formaram sem ter puncionado uma veia (...) (S.13).

Tenho sentimento de alegria, porque ensinei a enfermagem (...) depois (a partir de 1980) vieram as enfermeiras e começaram a tomar conta dessa parte da enfermagem' (ensino), acho que o médico tem que estar consciente de que deve 'ensinar todo mundo', aprender também, com a enfermagem, porque as enfermeiras hoje são de curso de nível superior, 
são pessoas que 'passam' a faculdade. O que seria dos médicos dentro do hospital sem as enfermeiras? (S. 10) (grifos nossos).

Em relação ao segundo grupo de relatos, realização e crescimento profissional/empregabilidade, foram evidenciados interesses e demandas institucionais diversos, decorrentes de novas tecnologias ou serviços de saúde. Através do ensino, os sujeitos buscavam atingir metas especíicas para muitos, conquistar o 'título' significava atingir sonhos de realização pessoal e profissional, enquanto para outros significava doação e entrega ao cuidado das pessoas. Formar-se na enfermagem era a chance de ser reconhecido profissionalmente, às vezes, entendido como uma possibilidade de "poderstatus' pela conquista da vaga de chefia de setor ou de um emprego diferenciado.

Foi o máximo me formar (Curso Técnico Enfermagem na década de 70). É mais ou menos como hoje se formar enfermeira (...) (S. 13)

(...) era uma honra, éramos as primeiras a ter um curso (...) aqui não tinha enfermeira, vieram bem mais tarde (S. 14).

Significa uma conquista muito grande, até pelo financeiro (S.27).

O curso valeu a pena, tanto que continuo até hoje (...) gosto de fazere de me dedicar ao próximo (S. 12).

(...) o significado para mim foi a realização de um sonho, queria fazer alguma coisa na área da saúde, estou satisfeita e muito feliz de poder ser chamada de enfermeira (S. 28).

Se, por um lado, houve alegrias e realizações, por outro lado, a formação também gerou angústia e sofrimento no momento em que muitos identificaram os riscos do despreparo para exercer uma profissão tão complexa, que exige tanta responsabilidade e preparo. Alguns sofreram ou sofrem ao lembrarem a trajetória deste aprendizado, baseado somente na prática da enfermagem. Talvez a origem desse sofrimento esteja no poder simbólico, na submissão e na obediência, pelo fato de os superiores (médicos, religiosas ou chefes) tomarem as decisões sobre aquilo que o outro deveria fazer, independente do significado atribuído pelo envolvido. Esses significados são entendidos como resultado da insegurança e do medo, decorrentes da falta de conhecimento para a prática da enfermagem.

Foi meio chocante (enquanto Atendente de Enfermagem), um pouco terrivel, eu desmaiava, me sentia mal, eu não podia ver morto (...) (S. 14).

No começo não gostava muito de trabalhar em hospital (...) fiz o curso para ter uma profissão (...) agora eu adoro (...) (S. 19).

Na época me sentia o máximo ser responsável pela sala (ambulatório). Fazia anestesia geral nos pacientes, o médico mandava e eu administrava a medicação (...) (S. 26).

Muitas coisas me marcaram, num dia saí da roça e no outro dia estava fazendo injeção sem noção nenhuma, uma semana depois eu estava trabalhando de noite sozinha, eu não sabia o que era soro glicosado ou soro fisiológico (...) (S. 13).

(...) a gente não foi preparada para isso, eu nunca imaginei ver uma pessoa ser preparada para colocar no caixão (...) (S. 14).

(...) eu não gostava era de ajudar o médico (em 1975) a dar o eletrochoque nos pacientes psiquiátricos (...) para mim era horrivel, muitas vezes depois do procedimento fui ao banheiro chorar (..). o pior foi quando tive que ajudar a fazer isto na minha melhor amiga (S.26).
Mesmo que para alguns sujeitos o ensino tenha causado sofrimento, tenha sido oneroso ou desgastante, ainda assim valeu a pena tanto aprender como ensinar as técnicas de enfermagem. Percebemos que houve uma significativa e incansável tendência dos sujeitos para a busca do saber da enfermagem.

(...) eram bastante caros, então a gente deixou de fazer um monte de coisas, mas pagávamos o curso, uma pedia auxilio paro o namorado, outra para o pai (...) (S. 06 ).

Para alguns, o ensino da enfermagem traz muitos benefícios, que vão além do mundo do trabalho; este ensino é agente de transformação e até mesmo permitem salvar vidas.

Salvei meu filho em casa, fiz a respiração boca a boca, se eu não tivesse esses conhecimentos de enfermagem, eu não saberia fazer, eu acho que aqueles cursos (Atendente de Enfermagem na década de 70) valeram para a vida, pois o conhecimento ninguém tira... achei muito importante e aproveitei, acho que valeu a pena, não só para quem ficou na enfermagem (...) (S. 08).

(...) a materno-infantil (disciplina do Curso Auxiliar de Enfermagem) contribuiu para mim como mãe e como profissional (...) devo muito do que sou enquanto pessoa à enfermagem (...) aprendi muito nesta profissão (...) (S. 26).

Estou cuidando do meu (familiar no hospital) vejo as pessoas trabalharem na enfermagem e às vezes eu penso que vou fazer a mesma tarefa de uma maneira diferente (S. 23).

Ao finalizarmos a descrição das falas dos sujeitos nesta categoria, percebemos que os significados do processo do ensino da enfermagem ea profissão guardam estreita relação com as atividades da vida, do cotidiano.

Borestein $^{(13)}$ afirma que (...) à medida em que se conhece a história de uma profissão, como em nosso caso, a da enfermagem, é nesse conhecimento que se percebe quanto e como a enfermagem não é inseparável de outras atividades da vida, do mundo da saúde e seus compromissos sociais.

\section{Categoria 05: 0 ensino da enfermagem e as políticas de saúde e} educação

A análise documental e as entrevistas evidenciaram uma forte relação entre o ensino da enfermagem e as políticas públicas de saúde e de educação, o que pode ser constatado através do histórico das respectivas legislações e dos currículos dos cursos pesquisados, nos níveis de ensino fundamental, médio, pós-médio e superior.

Entre os entrevistados que participaram do processo de ensino nas décadas de 70 a 90 , houve predomínio do enfoque terapêutico, técnico, ou seja, hospitalar, evidenciado nas entrevistas e nos currículos, cujas disciplinas apresentam enfoque biologicista e patológico. Os estágios, por sua vez, também eram centrados na área hospitalar. Na saúde pública, os alunos faziam inicialmente apenas um pequeno estágio, chamado de 'complemento'. À medida que as políticas foram sendo modificadas, o ensino foi se adequando. Atualmente, na graduação, há uma forte tendência à busca do equilibrio entre as ações curativas e as preventivas. Quanto ao ensino do Técnico em Enfermagem, percebemos nas falas dos sujeitos e na análise dos currículos, presença ainda marcante do enfoque voltado à complexidade hospitalar, havendo menor ênfase na abordagem preventiva.

O aprendizado das práticas de enfermagem até meados da década de 70 era baseado em atividades do dia-a-dia, ou seja, aquele que estava mais tempo na enfermagem ensinava aquele que estava iniciando, dentro de suas possibilidades e limitações. O foco do ensino informal para preparar atendentes de enfermagem estava totalmente centrado na área hospitalar, ou conforme planejamento e expectativa dos organizadores. Naquela época, os 
procedimentos na enfermagem eram realizados sem uma base científica apenas seguiam o modelo da repetição do fazer, caracterizando a divisão social e técnica do trabalho da enfermagem.

Esta divisão, na opinião de Rezende ${ }^{(1)}$, submete-se à forma de economia vigente no país, pois "As tarefas do fazer manual, legado das classes socialmente inferiores, contrapõem-se às atividades intelectuais, apanágio das elites pensantes, mesmo quando estas "elites", aspirantes do poder, têm subsumida sua força de trabalho ao capital"

ParaAlmeida e Rocha ${ }^{(12)}$, o capitalismo requer esta divisão do trabalho, tanto a divisão intelectual/manual, como em relação à classe a que os indivíduos que o executam pertencem, ou seja, o subordinado que pertence a uma classe social inferior executará as tarefas de repetição, sendo, na maioria das vezes, comandado por profissionais de maior qualificação intelectual e pertencentes a uma classe social mais elevada.

O trabalho "mais simples" da enfermagem será então executado pelos atendentes, que podem ser considerados os "operários" deste cuidado. O seu treinamento é feito no próprio local de trabalho (...)". E continua: "O trabalho dito mais simples que thes é atribuído é uma questão falsa, pois este mais simples é o cuidado do paciente, que é o objeto de trabalho da enfermagem.

Esta forma de ação estava de acordo com as políticas de saúde, o que não gerava demandas para outras áreas da enfermagem. Os primeiros cursos tinham como objetivo apenas treinar trabalhadores do hospital, para atender melhor o paciente e para auxiliar o médico, pois, segundo relatos, partiu deles a preocupação em aperfeiçoar ou treinar pessoas que, na maioria das vezes, já estavam trabalhando na enfermagem do hospital. Esta realidade no ensino da enfermagem foi se modificando e se adequando às diretrizes vigentes ao longo das décadas.

Os médicos sentiram que nos estávamos muito por fora, então eles começaram a fazer um curso e cada um dava sua especialidade (...) (S. 06).

(...) todo mundo tinha interesse que nós aprendêssemos... para poder auxiliar eles (os médicos), então todo mundo abria as portas, era mais fácil (...) (S. 05).

(...) entrei direto para a enfermagem, era as irmãs ou as gurias que estavam a mais tempo que ensinavam a gente a fazer as coisas, a fazer injeção (S.14).

(...) acho que hoje a enfermagem está perfeita ao ser comparada como tempo que eu comecei, agora ninguém mais faz injeção sem saber o que pode acontecer (...) (S. 13).

Como professora demorei muito para modificar a ênfase que era dada ao ensino das técnicas básicas de enfermagem.(S. 26).

No âmbito da prevenção de doenças e promoção da saúde, constatamos que alguns alunos eram incentivados a desenvolverem pequenos estágios com o objetivo de exercitar a prática da educação sanitária, tratando de temas como higiene e vacinas. Percebemos que as atividades eram realizadas nos bairros pobres, em forma de visitas, mini-estágios e palestras. No entanto, a abordagem dessas atividades era unilateral, ou seja, apenas a enfermagem ensina e a família aprende, desconsiderando saberes e culturas dos envolvidos.

(...) íamos lá pra ensinar como manter a higiene da casa, como fazer a higiene das mamadeiras das crianças, como cuidar do recém-nascido (...) prevenção da mulher (...) a gente reunia a 'mulherada' (...) a gente via que eles tinham muita pouca vontade e não faziam muita questão de aprender (...). vimos um monte de roupas em cima de lenha, apodrecendo, roupa boa que o pessoal trazia, elas não lavavam, elas jogavam fora. Isso me revoltou muito (S. 02).
Em Lajeado (1975) só tinha um posto de saúde, agora tem vários (...) (S.13).

(...) faziam um mini estágio fora do hospital para terem a experiência e orientar as famílias a cuidar da saúde a se prevenir(S. 16).

(...) o ensino era mais voltado a área hospitalar, apenas alguma coisas de saúde pública (S. 06).

(...) embora o curso tivesse disciplina de saúde pública eles faziam pouco estágio (S. 01).

Constatamos, através de relatos, que, no final da década de 80 , havia grande número de trabalhadores com prática na enfermagem, porém, muita carência de trabalhadores habilitados conforme exigências legais. A partir desta época, ocorre a expansão do ensino da enfermagem, que contribuiu para consolidar cada vez mais a profissão em nível regional. Este processo se desenvolve atrelado às novas as políticas de educação e saúde e ao fortalecimento dos órgãos de classe.

(...) estavam faltando trabalhadores qualificados (em meados de 1980). Tinha muitas pessoas boas trabalhando na enfermagem mas a formação era muito baixa (...) agora o pessoal que trabalha tem um nivel muito bom (...) a gente vê que houve crescimento do pessoal (...) na época (no início da década de 90), como não poderia mais ter os atendentes, o técnico ficou muito disputado, isso é muito bom, porque dai o profissional ficou escasso, e passou a ser valorizado. Em 1995, tinham vacinadores, que não eram nem atendentes, eram pessoas treinadas para fazer vacina (...) as prefeituras começaram a fazer concursos e isso e modificou o perfil dos municípios (...) (S. 07).

(...) demanda maior no curso de auxiliar ainda era para trabalhar no hospital (...) o curso também precisou se adequar as novas diretrizes de ensino e do conselho de enfermagem e isso acabou se tornando um atrativo (...) um fator positivo para os cursos de enfermagem (S.24).

Na região, a partir da década de 90 , foi enfatizado o conhecimento relacionado à prevenção de doenças, que coincide com a implantação de muitos programas de saúde pública, como o Programa de Saúde da Família e a expansão das municipalizações no Vale do Taquari.

Por outro lado, ficou evidente, especialmente nos últimos anos, a preocupação dos organizadores dos cursos e professores da enfermagem com os valores morais e éticos das relações humanas e 0 atendimento à saúde preventiva.

(...) os estágios eram no hospital e no posto (...) foi bastante saúde pública (Curso de Bacharelado de Enfermagem) (S. 17).

(...) além das matérias básicas, a ética, o compromisso com a profissão em levar a sério, o julgamento das pessoas, a prevenção é bastante forte (...) (S.27)

(...) a enfermagem na (IES) se preocupou em dividir o lado hospitalar e o lado de saúde pública (S. 28).

O foco foi o paciente/cliente, ter um cuidado especial que envolve o todo, fisicamente, espiritualmente (S. 20).

Insistiam no calor humano, na técnica também (...) carinho faz mais que um remédio (...) (S. 23).

(...) um ensino de qualidade, um bom profissional que tivesse condições 
Hahn GV, et al.

de fazer um bom trabalho (...) (S. 15).

\section{CONSIDERAÇÕES FINAIS}

Finalizando este artigo, vale ressaltar que a construção dos saberes e das práticas de enfermagem em Lajeado é semelhante ao que está registrado na literatura, em relação a outros locais. Inicialmente, os ocupacionais da enfermagem eram treinados por médicos e trabalhadores com maior tempo de serviço e de prática para atender às necessidades hospitalares através do ensino informal. Neste caso, as pessoas iniciavam suas atividades na área hospitalar como leigos. Os primeiros cursos formais (Auxiliar de Enfermagem) ocorreram no próprio hospital, organizados pelos enfermeiros, cujo enfoque era patológico e hospitalocêntrico. A crescente demanda em termos de atendimento à saúde estimulou a criação do primeiro curso Técnico de Enfermagem em Lajeado, em uma escola de ensino fundamental e médio, para qualificar a mão-de-obra existente e preparar novos profissionais. Porém, o enfoque continuava sendo biologicista, com pouca compreensão da promoção da saúde e da prevenção de doenças.

Constatou-se, também, que grande parcela de alunos fez mais de um curso na área da enfermagem. A busca do conhecimento, num primeiro momento, foi motivada, em grande parte, pelo próprio trabalho hospitalar; porém, hoje, isto raramente ocorre. Na época, os trabalhadores ingressavam nos hospitais muito cedo. Algumas jovens eram ainda meninas e seguiam carreira em escala ascendente, ou seja, iniciavam na limpeza, passavam para a copa (nutrição) e após, para a enfermagem.

Constatou-se, também, que tanto o ingresso no hospital como a qualificação através do ensino partia de convite feito por religiosas, médicos, parentes ou amigos, prevalecendo a idéia de que a pessoa "tinha jeito para trabalhar na enfermagem" ou "tu dá para isso". Posteriormente, buscava-se formação específica na enfermagem em outros niveis, seguindo a orientação apresentada pela Lei do Exercício Profissional, $n^{\circ} 7498 / 86$.

O presente estudo mostrou, também, que, ao longo do tempo, a procura pelo saber da enfermagem foi se modificando. Nas primeiras entrevistas, as pessoas verbalizavam adquirir o conhecimento através da prática, em alguns casos, induzidos pelos seus superiores. Já os demais buscam o saber da enfermagem espontaneamente, principalmente a partir de necessidade sócioeconômica, com o intuito de construir uma profissão, ou seja, desenvolver competências e habilidades específicas que possibilitem o ingresso no mundo do trabalho da enfermagem, levando em consideração as orientações expressas nas Diretrizes Curriculares Nacionais para o curso de enfermagem.

Observou-se que novos cursos vão sendo estruturados à medida que surgem demandas no mercado de trabalho, o que culminou com o Ensino Superior em Enfermagem, em Lajeado. Alguns cursos surgiram apenas para atender a determinado objetivo, sendo, posteriormente, cancelados. Arealização de cursos para atingir objetivos mais imediatos gerou muitas irregularidades. No entanto, houve mudanças no momento em que ocorre a continuidade e as escolas assumem o papel de formadoras.

A pesquisa também evidenciou que o ensino solidificou-se de forma progressiva, em nível local e regional, para atender às necessidades do mercado, ou seja, a escola é colocada a serviço do mundo do trabalho. No momento em que as instituições formais de ensino assumem o processo de formação de trabalhadores, ocorre esta solidificação, a partir da necessidade das instituições de saúde, que buscam pessoas especializadas para trabalhar nas diferentes áreas da saúde, hospitalares ou públicas (Programa de Saúde da Família, Unidades Básicas de Saúde, clínicas privadas, consultórios médicos, hospitais, entre outros).

No período em estudo, observamos uma lacuna na história, pois encontramos relatos somente a partir da década de 70 , quando ficou claro que o ensino da enfermagem estava voltado à profissionalização de acordo com demandas hospitalares. O ensino tinha como foco o 'treinamento' para reproduzir atividades da enfermagem hospitalar.

Por outro lado, os cursos realizados em estabelecimentos de ensino seguiam os trâmites recomendados pelas políticas da educação e da saúde.

Há indicativos de que o ensino da enfermagem perpassa o desenvolvimento e a história das instituições pesquisadas e que, em vários momentos, foram estabelecidas importantes parcerias para o êxito da formação, algumas perdurando até os dias de hoje.

Percebemos, entre os entrevistados, o reconhecimento pelo esforço e a busca constante por qualidade e aperfeiçoamento por parte daqueles que atualmente levam à frente o processo de formação de enfermagem em Lajeado.

Concluímos que o movimento de profissionalização da enfermagem através do ensino foi intenso nos últimos 50 anos, através da iniciativa de diversos atores vinculados a hospital e escolas, o que está contribuindo para a profissionalização da enfermagem, tendo em vista uma consciência maior do real trabalho da enfermagem e da sua importância para a qualidade de vida da população.

\section{REFERÊNCIAS}

1. Rezende ALM. Saúde dialética do pensar e do fazer. São Paulo (SP): Cortez; 1986.

2. Rizzotto MLF. História da enfermagem e sua relação com a saúde pública. Goiânia (GO): AB; 1999.

3. Félix LO. História e Memória: a problemática da pesquisa. Passo Fundo (RS): EDIUPF; 1998.

4. Bardin L. Análise de Conteúdo. Lisboa (POR): Edições 70; 1977.

5. Silva MK. Uma introdução à História Oral. Cad Sociologia 1994; 9: $115-41$

6. Pires D. Hegemonia médica na saúde e enfermagem. São Paulo (SP): Cortez; 1989

7. Silva GB. A enfermagem profissional: análise crítica. $2^{\mathrm{a}}$ ed. São Paulo (SP): Cortez; 1989

8. Foucault M. Microfísica do poder. São Paulo (SP): Graal; 2003.
9. Schierholt JA. 100 anos de Madre Bárbara. Lajeado (RS): CDU; 1997.

10. Saldanha OL, Schwingel G. Os trabalhadores em saúde na região do Vale do Taquari: uma breve análise da evolução quantitativa, período 2000-2002. Boletim da Saúde 2002; 16(1).

11. Moreira AR. Repensando os princípios de Florence Nightingale para a prática atual em saúde coletiva (monografia). Florianóplois (SC): Universidade Federal de Santa Catarina; 2004.

12. Almeida MCP, Rocha JSY. O saber da enfermagem e sua dimensão prática. São Paulo (SP): Cortez; 1989.

13. Borenstein MS. O cotidiano da enfermagem no Hospital de Caridade de Florianópolis, no período de 1953 a 1968 (monografia). Florianópolis (SC): Universidade Federal de Santa Catarina; 2000. 